\title{
Airborne intercomparison of vacuum ultraviolet fluorescence and tunable diode laser absorption measurements of tropospheric carbon monoxide
}

\author{
John S. Holloway, 1,2 Roger O. Jakoubek, ${ }^{1}$ David D. Parrish,1 Christoph Gerbig, ${ }^{3,4}$ \\ Andreas Volz-Thomas, ${ }^{3}$ Sandra Schmitgen, ${ }^{3}$ Alan Fried, ${ }^{5}$ Brian Wert, 5 Bruce Henry, 5 \\ and James R. Drummond6
}

\begin{abstract}
During the fall 1997 North Atlantic Regional Experiment (NARE 97), two separate intercomparisons of aircraft-based carbon monoxide measurement instrumentation were conducted. On September 2, CO measurements were simultaneously made aboard the National Oceanic and Atmospheric Administration (NOAA) WP-3 by vacuum ultraviolet (VUV) fluorescence and by tunable diode laser absorption spectroscopy (TDLAS). On September 18, an intercomparison flight was conducted between two separate instruments, both employing the VUV fluorescence method, on the NOAA WP-3 and the U.K. Meteorological Office C-130 Hercules. The results indicate that both of the VUV fluorescence instruments and the TDLAS system are capable of measuring ambient $\mathrm{CO}$ accurately and precisely with no apparent interferences in $5 \mathrm{~s}$. The accuracy of the measurements, based upon three independent calibration systems, is indicated by the agreement to within $11 \%$ with systematic offsets of less than $1 \mathrm{ppbv}$. In addition, one of the groups participated in the Measurement of Air Pollution From Satellite (MAPS) intercomparison [Novelli et al., 1998 ] with a different measurement technique but very similar calibration system, and agreed with the accepted analysis to within 5\%. The precision of the measurements is indicated by the variability of the ratio of simultaneous measurements from the separate instruments. This variability is consistent with the estimated precisions of $1.5 \mathrm{ppbv}$ and $2.2 \mathrm{ppbv}$ for the $5 \mathrm{~s}$ average results of the C-130 and the WP- 3 instruments, respectively, and indicates a precision of approximately $3.6 \%$ for the TDLAS instrument. The excellent agreement of the instruments in both intercomparisons demonstrates that significant interferences in the measurements are absent in air masses that ranged from $7 \mathrm{~km}$ in the midtroposphere to boundary layer conditions including subtropical marine air and continental outflow with embedded urban plumes. The intercomparison of the two VUV instruments that differed widely in their design indicates that the VUV fluorescence technique for $\mathrm{CO}$ measurements is not particularly sensitive to the details of its implementation. These intercomparisons help to establish the reliability of ambient $\mathrm{CO}$ measurements by the VUV fluorescence technique.
\end{abstract}

\section{Introduction}

Carbon monoxide ( $\mathrm{CO}$ ) is a ubiquitous trace constituent of the troposphere. Annual mean concentrations at isolated sites range from 55 parts per billion by volume (ppbv) in the Southern Hemisphere to $155 \mathrm{ppbv}$ in the northern, with considerable regional and seasonal variability about these means [Novelli et al., 1992]. CO is a major primary emission

\footnotetext{
IAeronomy Laboratory, NOAA, Boulder, Colorado.

2Cooperative Institute for Research in Environmental Sciences, University of Colorado, Boulder.

3Institut für Chemie und Dynamik der Geosphåre, Forschungszentrum Juilich, Jiilich, Germany.

4Now at Department of Earth and Planetary Sciences, Division of Engıneering and Applied Sciences, Harvard University, Cambridge, Massachusetts.

5National Center for Atmospherıc Research, Boulder, Colorado.

6Department of Physics, Unıversity of Toronto, Toronto, Ontario, Canada.

Copyright 2000 by the American Geophysical Union

Paper number 2000JD900237.

0148-0227/00/2000JD900237\$09.00
}

from fossil fuel combustion and biomass burning; concentrations in regional pollution plumes can reach 400 ppbv or more [Singh et al., 1996; Parrish et al., 1998]. The lifetime of $\mathrm{CO}$ in the atmosphere varies from 1 month in summer to 3 months in winter [Seinfeld, 1986]; this long lifetime makes possible the use of $\mathrm{CO}$ as a quasi-conservative tracer for anthropogenic emissions [Fishman and Seiler, 1983]. As a conserved surrogate for more photochemically active compounds, in particular the reactive nitrogen family, $\mathrm{CO}$ shows strong positive correlations with $\mathrm{O}_{3}$ of photochemical origin [Parrish et al., 1993]. In contrast, the stratosphere is depleted in $\mathrm{CO}$ and rich in $\mathrm{O}_{3}$ so that $\mathrm{CO}$ is negatively correlated with $\mathrm{O}_{3}$ of stratospheric origin. Such relationships provide tools to 1dentify and isolate the processes affecting $\mathrm{O}_{3}$ in an air mass [Newell et al., 1996; Parrish et al., 1998].

Routine techniques with sufficient accuracy, precision, and time resolution exist for observations of $\mathrm{CO}$ at surface sites. Grab sampling followed by gas chromatographic (GC) analysis [Rasmussen and Khalil, 1982] has been widely utilized. Novelli et al. [1992] derived the latitudinal and seasonal variations of $\mathrm{CO}$ from grab samples collected from a global 
sampling network. Nondispersive infrared absorption spectroscopy (NDIR) [Dickerson and Delany, 1988] provides continuous measurements with a precision that can approach 1 ppbv for a 1 hour average [Parrish et al., 1994].

In contrast, airborne measurements require rapid time response with high precision [Albritton et al., 1990]. The tunable diode laser absorption spectroscopy (TDLAS) method of Sachse et al. [1987] has been the technique of choice for aircraft measurements because it can provide a precision of \pm 1 ppbv in $\approx 1 \mathrm{~s}$. High spectroscopic specificity makes this method additionally attractive for ambient measurements. The TDLAS method has been intercompared with GC [Hoell et al., 1987] and NDIR [Fried et al., 1991] techniques; each study found excellent agreement with no evidence of ambient interferences. One significant disadvantage of the TDLAS method is that it is technologically demanding.

Volz and Kley [1985] described a fluorometric method based on the $\mathrm{CO}$ fourth-positive electronic band system in the vacuum ultraviolet (VUV). This method has since been more extensively examined, and results of aircraft based measurements have been reported [Gerbig et al., 1996; 1999]. While the precision and time response of the technique are comparable to those of the TDLAS system, much simpler instrument operation is possible. Below we describe a VUV fluorescence instrument that is installed in the unpressurized wing pod of an aircraft and operates completely automatically. At present, the VUV fluorescence technique is becoming even more widely used than the TDLAS method. In addition to instruments described below and deployed on the U.K. Meteorological Office's C-130 Hercules and the National Oceanic and Atmospheric Administration (NOAA) WP-3 Orion, VUV fluorescence instruments are used on two German research aircraft (A. Volz-Thomas, private communication, 1999) and on Japan's G-2 aircraft during the Biomass Burning and Lightning Experiment (BIBLE) campaign ( $Y$. Kondo, private communication, 1999). A commercial version of the VUV fluorescence instrument is available (AERO-Laser, Garmisch Partenkirchen, Germany), so additional deployments will likely follow. One concern, however, is that there are no reports of intercomparisons of the VUV fluorescence technique with other methods. Such intercomparisons are critical to establish the reliability of the growing VUV fluorescence CO data set.

We report here the results of two intercomparisons conducted during the 1997 North Atlantic Regional Experiment (NARE 97): an informal intercomparison between a VUV fluorescence instrument and a TDLAS system on the same aircraft, and a blind intercomparison between two VUV fluorescence instruments of different design and operation deployed on different aircraft. The measurement accuracy, precision, and the possibility of ambient measurement interferences of the VUV fluorescence technique are evaluated from the degree of agreement between the different measurements. There was no intercomparison referee to provide prepared samples to independently assess the absolute accuracy of the instruments. There is, however, an independent assessment of the accuracy of the calibration procedures used by one of the participating groups; they were also involved in the Measurement of Air Pollution From Satellite (MAPS) intercomparison [Novelli et al., 1998]. Here, using an NDIR instrument, but a nearly identical calibration system, they agreed with the accepted analysis to within 5\% throughout the investigated concentration range. In this paper we briefly describe the instruments (section 2), present the results of the two intercomparisons (sections 3 and 4), and discuss the conclusions regarding the accuracy, precision, and possible interferences of the VUV fluorescence technique (section 5). Since the VUV intercomparison was conducted under a formal, blind protocol, the data as submitted are first compared, and the causes of observed differences are subsequently discussed.

\section{Instruments}

The TDLAS and VUV fluorescence techniques have been described in the literature. Here we will give brief overviews of each instrument and those specifics required for discussion of the intercomparison results. The TDLAS system used here was developed for the measurement of formaldehyde; it was adapted to the measurement of $\mathrm{CO}$ only for this one intercomparison flight. Thus the TDLAS performance is not representative of a system optimized for the measurement of CO. Table 1 summarizes the performance parameters of the VUV instruments.

\subsection{NCAR TDLAS Instrument}

Wert et al. [1998] describe the airborne TDLAS instrument developed at the National Center for Atmospheric Research (NCAR), and Fried et al. [1998a, b; 1999] give comprehensive details regarding instrument performance and various aspects of the sampling inlet. The IR radiation from a lead-salt diode laser is collected and focused into the center of a 3-L multipass astigmatic Herriott cell (Aerodyne Inc.) by a pair of $90^{\circ}$ offaxis ellipsoidal mirrors. The total optical path length of the measurement is $100 \mathrm{~m}$ (182 passes of the $55 \mathrm{~cm}$ base path). The output beam is focused onto an InSb detector using an $\mathrm{f} / 1 \mathrm{BaF}_{2}$ plano-convex lens. Approximately once a minute a lifting stage in the optical path blocks the laser beam for measurement of detector background levels.

Approximately $10 \%$ of the beam was split off by a $\mathrm{BaF}_{2}$ window and directed onto a second InSb detector through a 15 $\mathrm{cm}$ reference cell containing a few Torr of pure $\mathrm{CO}$. This signal provided a wavelength reference to lock the laser output to the center of the $\mathrm{CO}$ absorption feature of interest: the $\mathrm{P}(18)$ line of ${ }^{12} \mathrm{C}^{16} \mathrm{O}$ at $2068.8469 \mathrm{~cm}^{-1}(4.83 \mu \mathrm{m})$. This line has an integrated absorption strength of $6.9 \times 10^{-20} \mathrm{~cm}^{2} / \mathrm{cm}$ molecule at $30^{\circ} \mathrm{C}$ (HITRAN database [Rothman et al., 1996]). Although the $\mathrm{CO}$ absorption cross sections in the $2172 \mathrm{~cm}^{-1}$ region are 6.8 times larger, these lines could not be accessed by the present diode laser. Ambient $\mathrm{CO}$ measurements were acquired by second harmonic detection coupled with sweep integration [Fried et al., 1991]. An ambient acquisition was acquired every $5 \mathrm{~s}$. After four such intervals, a $10 \mathrm{~s}$ background spectrum was acquired by overflowing the inlet with zero air, produced in situ by passing ambient air over a heated $\mathrm{Pd}(0.5 \%$ on alumina) catalyst. This zeroing procedure is designed to effectively capture and remove optical noise. However, in the case of $\mathrm{CO}$, optical variability was found to be of roughly the

Table 1. Instrumental Parameters for Intercomparisons

\begin{tabular}{lll}
\hline & NOAA WP-3 & Jülich C-130 \\
\hline Sensitivity* & $79 \mathrm{cps} / \mathrm{ppbv}$ & $73 \mathrm{cps} / \mathrm{ppbv}$ \\
1 s precision (5 s) & $2.2 \mathrm{ppbv}$ & $1.5 \mathrm{ppbv}$ \\
Background $\dagger$ & $124 \mathrm{ppbv}$ & $64 \mathrm{ppbv}$ \\
\hline
\end{tabular}

*Photon counts per second per ppbv CO.

†Equivalent ppbv CO. 
same magnitude as scrubber breakthrough $(\approx 0.5 \%)$, so the data reported here were determined without the use of background subtraction.

No significant interferences in the measurement of $\mathrm{CO}$ are expected. The HITRAN database [Rothman et al., 1996] lists a number of absorption features from $\mathrm{H}_{2} \mathrm{O}, \mathrm{OCS}, \mathrm{O}_{3}$, and $\mathrm{CO}_{2}$ near the $\mathrm{P}(18)$ CO line. Previous work [Fried et al., 1991] has shown that at ambient atmospheric levels, the presence of these gases can lead to a maximum error of $0.5 \%$ in the $\mathrm{CO}$ measurement. Spectral calculations employing the range of water vapor mixing ratios encountered during the flight of September 2 indicate a $\mathrm{CO}$ measurement error of no more than $+0.5 \%$. These calculations model second harmonic absorption profiles of the various species involved and include the indirect effect of changes in pressure broadening due to variations in $\mathrm{H}_{2} \mathrm{O}$ concentration [Sachse et al., 1987].

The sample inlet [Fried et al., 1998a], designed for artifactfree sampling of formaldehyde, caused some minor problems in the calibration of $\mathrm{CO}$. It is a rearward facing, 1 inch OD glasslined stainless steel tube heated to $35{ }^{\circ} \mathrm{C}$ to within a few centimeters of the inlet entrance that extends past the aircraft boundary layer and continuously draws ambient air through the Herriott cell at a flow rate of 7.5 standard liters per minute (sLpm) and a pressure of 25 Torr. The cell receives the central $80 \%$ of the inlet flow; the remainder is split off to minimize sample interaction with the walls of the inlet. For $\mathrm{CO}$ calibration, $50 \mathrm{~cm}^{3}$ per minute at STP $\left(\mathrm{cm}^{3} \mathrm{~min}^{-1}\right.$ STP) of a 42 ppm National Institute of Standards and Technology (NIST) CO standard reference material (SRM) were injected as a standard addition to the zero air flow. The flows employed generated CO/arr mixtures of $239 \mathrm{ppbv}$. In-flight calibrations were performed every $20 \mathrm{~min}$.

Since the total inlet flow was not sampled, accurate calibration requires that the standard be uniformly mixed into the zero air matrix before the flow was divided. Using a flow rate of $50 \mathrm{~cm}^{3} \mathrm{~min}^{-1} \mathrm{STP}$, both field tests and postmission laboratory tests indicate that the degree of mixing in the inlet is sensitive to small variations in the standard flow rate. The measured instrument response derived from the individual flight calibrations during the intercomparsson exhibited a scatter $(1 \sigma=3.7 \%$ ) approximately twice that expected on the basis of instrument diagnostics. The magnitude of the scatter was attributed to variability in the mixing of the calibration standard into the sample flow. Rather than utilize the individual calibrations, the ambient data were fit to a single flight calibration spectrum representative of the average of all the flight calibrations. More uniform mixing was achieved for the subsequent $\mathrm{CH}_{2} \mathrm{O}$ measurements by employing significantly larger standard flows.

Ambient $\mathrm{CO}$ concentrations were obtained by fitting the ambient spectra to the calibration spectra employing a multıple linear regression approach. A measurement precision of less than 1 ppbv was achieved in $5 \mathrm{~s}$ of averaging. The total measurement uncertainty was calculated by quadrature addition of the various random and systematic error sources. Because of uncertainties in the calibration mixing, we report a lower and upper $1 \sigma$ total uncertainty of 2.7 and $5.7 \%$. In addition to the mixing considerations, this analysis includes systematic uncertainty estimates in the SRM calibration concentration, flow ratios, and the use of a single calibration spectrum, and random estimates based upon the instrument precision ( $\leq 0.9 \mathrm{ppbv}$ in $5 \mathrm{~s}$ of averaging), as well as pressure and laser power corrections.

\subsection{Fundamentals of VUV Resonance Fluorescence}

Volz and Kley [1985] first discussed the physical fundamentals of the $\mathrm{CO}$ fluorescence measurement. The $A^{1} \Pi$ $\rightarrow X^{1} \sum$ electronic transition is the first fully allowed transition In the $\mathrm{CO}$ electronic manifold. It has a radiative lifetime of $10.7 \mathrm{~ns}$ [Imhof and Read, 1971]. Accordingly, the oscillator strength, and therefore the absorption cross section of individual rotational/vibration transitions within the electronic system, are expected to be large. We estimate peak cross sections of individual transitions to be of the order of 2-9 $x 10^{-15} \mathrm{~cm}^{2}$. Although collisional quenching of the $A$ state is efficient $\left(k=2.3 \times 10^{-10} \mathrm{~cm}^{3} / \mathrm{s}\right.$ for $\left.\mathrm{N}_{2}[F i n k, 1976]\right)$, the short excited state lifetime ensures that fluorescence dominates over collisional quenching at pressures below about 10 Torr [Volz and Kley, 1985]. The system exhibits significant off-diagonal Franck-Condon strength [Nicholls, 1962], so that excitation of the transition occurs at wavelengths to the blue of the main body of fluorescence. This allows efficient discrimination between the excitation radiation (155 to $140 \mathrm{~nm}$, the location of the first five vibrational bands of the $v^{\prime \prime}=0$ progression), and the resulting fluorescence $(>\approx 170 \mathrm{~nm})$.

Discrete electronic transition bands are composed of individual, Doppler broadened rotational lines. Fluorescence excitation with resonance rather than broadband radiation largely limits the source of interference from other atmospheric species to continua absorptions. Such transitions are weak with respect to bound-bound transitions. In the region of the $\mathrm{CO}$ fluorescence excitation, potential interferences from common atmospheric species are limited to $\mathrm{O}_{2}, \mathrm{CO}_{2}$, and $\mathrm{H}_{2} \mathrm{O}$.

Molecular oxygen absorbs at wavelengths below about 195 $\mathrm{nm}$. Absorption of excitation light by $\mathrm{O}_{2}\left(\sigma=1.2 \times 10^{-17} \mathrm{~cm}^{2}\right.$ at $150 \mathrm{~nm}$ [Okabe, 1978]) necessitates that the fluorescence measurement take place at reduced pressure, a constraint also placed on the system by collisional quenching. In addition to attenuation of the excitation light, fluorescence from atmospheric $\mathrm{O}_{2}$ is the principal source of the instrument background. The cause of this emission has been attributed to resonance Raman scattering by electronically excited $\mathrm{O}_{2}$ [Gerbig et al., 1996]. Since the same wavelengths of radiation that are responsible for the fluorescence excitation of $\mathrm{CO}$ excite this Raman background, the effect places a physical limit on the precision of the fluorescence measurement technique.

The absorption cross section of $\mathrm{CO}_{2}$ is about $6 \times 10^{-19} \mathrm{~cm}^{2}$ in the 155 to $140 \mathrm{~nm}$ region [Inn et al., 1953]; the attenuation of the excitation light by $\mathrm{CO}_{2}$ is insignificant at tropospheric levels. Absorption of the excitation light by atmospheric water vapor at the reduced pressures necessitated by the $\mathrm{O}_{2}$ absorption is also negligible due to a local absorption minimum $\left(\sigma \approx 1.1 \times 10^{-18} \mathrm{~cm}^{2}\right.$ at $150 \mathrm{~nm}$ ). The absorption spectrum of $\mathrm{H}_{2} \mathrm{O}$, however, exhibits a local maximum $(\sigma \approx 6 \mathrm{x}$ $10^{-18} \mathrm{~cm}^{2}$ at $170 \mathrm{~nm}, \sigma \approx 9 \times 10^{-19} \mathrm{~cm}^{2}$ at $180 \mathrm{~nm}$ ), which presents the potential for absorbing the $\mathrm{CO}$ fluorescence [Watanabe and Zelikoff, 1953]. The nature of the interference is complicated by the fact that $\mathrm{H}_{2} \mathrm{O}$ in an ambient sample displaces some ambient $\mathrm{O}_{2}$. The magnitude of these effects will be dependent on the geometry employed to excite and detect $\mathrm{CO}$ fluorescence. Analysis of the NOAA VUV fluorescence instrument indicates that the fluorescence is attenuated by $0.3 \%$ attenuation per percent mixing ratio of $\mathrm{H}_{2} \mathrm{O}$ in the sample $\left(\% / \% \quad \mathrm{H}_{2} \mathrm{O}\right)$. Displacement of the corresponding mixing ratio of $\mathrm{O}_{2}$ by $\mathrm{H}_{2} \mathrm{O}$ results in an increase of about $0.5 \% / \% \mathrm{H}_{2} \mathrm{O}$ in excitatıon intensity within the field of view of 
the fluorescence detection. Thus these effects tend to cancel one another. Laboratory tests demonstrate a negative interference of $0.26( \pm 0.17) \% / \% \mathrm{H}_{2} \mathrm{O}$. A second potential interference from water vapor also exists. Absorption of light by $\mathrm{H}_{2} \mathrm{O}$ below about $136 \mathrm{~nm}$ results in the production of an electronically excited $\mathrm{OH}$ fragment. Fluorescence from this excited $\mathrm{OH}$ would constitute a positive interference. It is necessary to either limit the excitation radiation to wavelengths longer than the $\mathrm{OH}$ fluorescence threshold, or to the dry the sample; the two instruments intercompared here chose different strategies.

\subsection{NOAA WP-3 VUV Fluorescence Instrument}

Figure 1 shows a schematic diagram of the VUV CO fluorimeter. The design closely follows the scheme suggested by Volz and Kley [1985]. The instrument consists of three modules (a resonance excitation source, an optical filter, and a sample fluorescence detection cell) plus associated plumbing and calibration components.

The resonance excitation source employs a dc glow discharge in a mixture of $0.26 \%$ by volume of $\mathrm{CO}_{2}$ in Ar. Carbon monoxide is created in the discharge rather than being added as a constituent of the gas mixture, which reduces the inherent self-absorption of resonance lamps. The gas mixture flows through the lamp at $50 \mathrm{~cm}^{3} \mathrm{~min}^{-1} \mathrm{STP}$ and a pressure of 7.0 Torr. Flowing gas minimizes the deposit of carbon from the discharge and further reduces self-absorption. A capillary $3.4 \mathrm{~mm}$ diameter by $70 \mathrm{~mm}$ in length contains the discharge region. The forced-air- cooled, Ni-plated $\mathrm{Al}$ cathode is held at approximately $-380 \mathrm{~V}$ with a constant current of $80 \mathrm{~mA}$. The anode is a $\mathrm{Ni}$ pin at ground potential. The emission spectrum of the lamp is similar to that reported by Volz and Kley [1985].

The optical filter is a crossed Czerny-Turner vacuum monochromator with a $50 \mathrm{~mm}$ diameter, 1200 groove $/ \mathrm{mm}$ plane grating blazed at $150 \mathrm{~nm}$ (Hyperfine, Inc) and $500 \mathrm{~mm}$ radius $\mathrm{Al} / \mathrm{MgF}_{2}$ mirrors (Acton Research Corp.). The grating is tuned such that the $(1,0)$ and $(2,0) \mathrm{CO}$ bands of the $A$ to $X$ electronic transition are fully transmitted. The optics provide $\mathrm{f} / 5$ performance with a transmission efficiency of about $25 \%$, and a band pass of $10 \mathrm{~nm}$ full width at half maximum (FWHM). Entrance and exit windows of $\mathrm{MgF}_{2}$ seal the monochromator from the light source and the fluorescence cell. The $5 \mathrm{~L}$ volume of the monochromator is purged once per minute by the $\mathrm{CO}_{2}$ /Ar gas mixture prior to its flow into the lamp. The pressure in the monochromator is 7.5 Torr; at that pressure the $\mathrm{CO}_{2}$ attenuates the excitation light by about $2 \%$.

The pathlength of the excitation light through the atmospheric sample in the fluorescence cell is $2.6 \mathrm{~cm}$ to the center of the line of sight of two solar blind photomultiplier tubes (PMTs) with $23 \mathrm{~mm}$ diameter RbTe photocathodes (model 9405Q, Electron Tubes Ltd). These PMTs collect fluorescence through synthetic fused silica windows with an aperture of $25 \mathrm{~mm}$; the shortwave cutoff of fused silica ( $<1 \%$ transmission at $160 \mathrm{~nm}$ ) provides the necessary discrimination against excitation wavelengths. The fluorescence pathlength of the cell is $1.4 \mathrm{~cm}$, which results in an $\mathrm{f} / 0.74$ performance for each PMT. Optical baffles in front of the windows block light scattered from the cell entrance window.

Figure 2 places the fluorimeter in the context of the analytical measurement. A single vacuum pump (Vacubrand, Elnik Systems) exhausts both the monochromator purge/lamp circuit and the sample flow through the fluorescence cell. Mass flow controllers maintain and measure all gas flows. The pressure in the fluorescence cell is held constant at 6.5 torr at a mass flow of approximately $180 \mathrm{~cm}^{3} \mathrm{~min}^{-1}$ STP by feedback from a capacitance manometer to the mass flow controller upstream of the cell.

The sensitivity of the instrument is determined by the standard addition of a small flow of $9.9 \mathrm{ppm} \mathrm{CO}$ in zero air to the ambient sample flow. The concentration of this field standard was determined by comparison to a CO Standard Reference Material from NIST. The instrument response in the absence of $\mathrm{CO}$ is obtained by passing the ambient sample over a propretary catalyst (R3-11, BASF Corp.) maintained at 150 ${ }^{\circ} \mathrm{C}$, which oxidizes $\mathrm{CO}$ to $\mathrm{CO}_{2}$. Tests indicate a $\mathrm{CO}$ removal efficiency of $\geq 99.8 \%$. Determination of sensitivity and background in ambient air accounts for any changes in instrumental response due to changes in the composition of the ambient sample.

The delay between sample acquisition and analysis is a function of the sample flow rate, the ambient pressure, and the volume of the sample lines upstream of the flow controller; it is always less than $3 \mathrm{~s}$. The data reported here have been corrected for this delay. The $1 / e$ instrumental time response as demonstrated by the response to standard addition calibrations is less than $2 \mathrm{~s}$ at all ambient pressures.

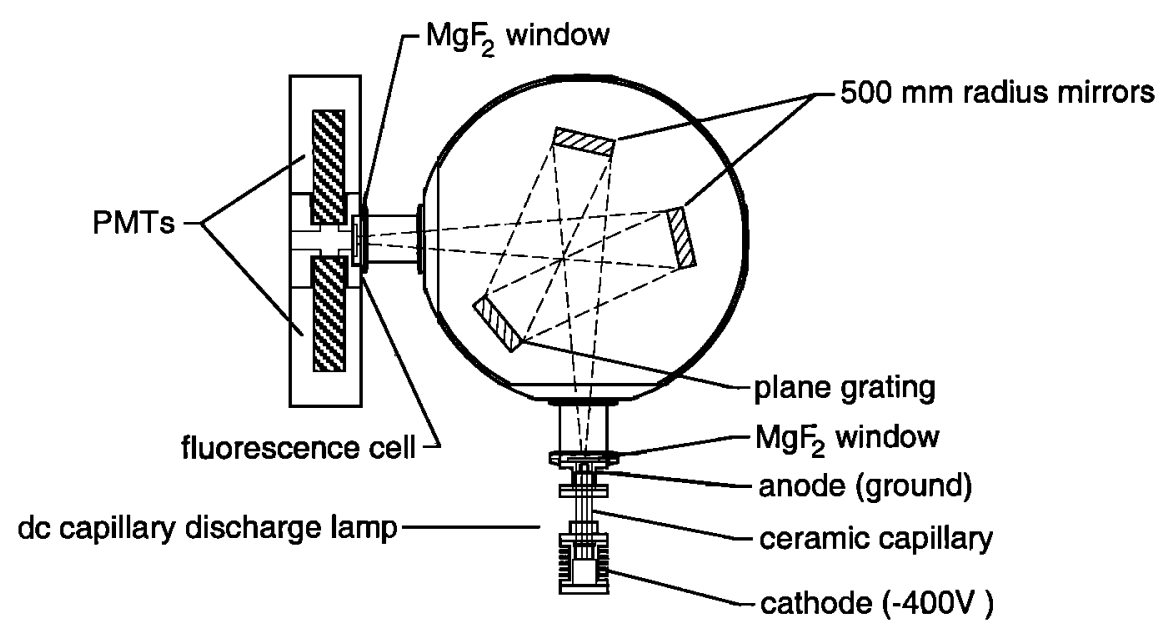

Figure 1. Schematic of the fluorimeter of the NOAA WP-3 VUV CO fluorescence instrument. 


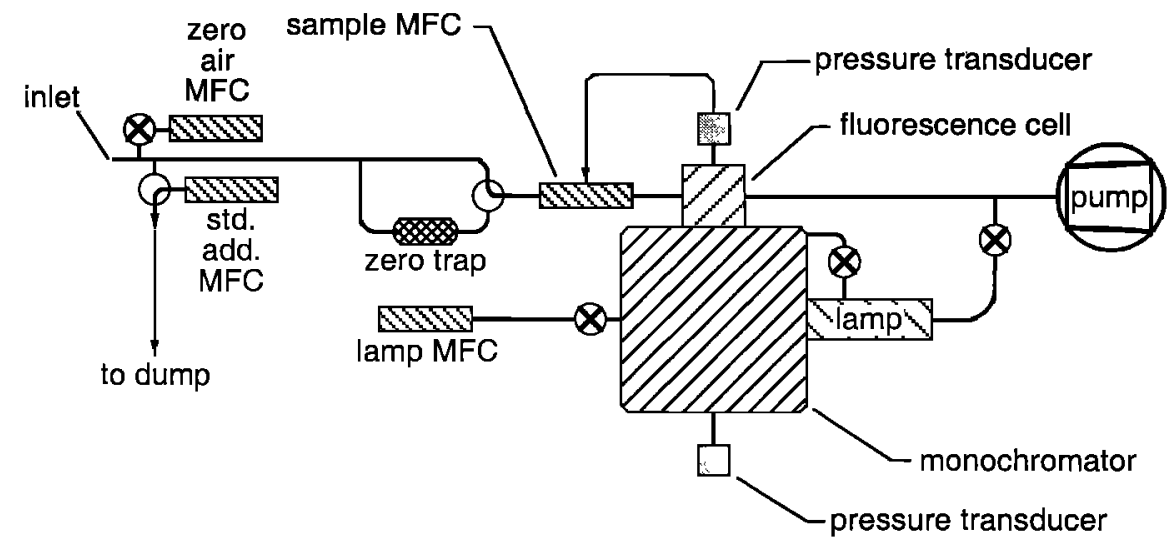

Figure 2. Schematic of the NOAA WP-3 VUV CO fluorescence instrument. MFC represents mass flow controller.

For the 1997 NARE campaign the CO instrument was deployed in a wing-mounted instrument pod. The operation in an unpressurized environment led to a negative dependence of the instrumental sensitivity on altitude of about $3 \% / \mathrm{km}$. This effect was primarily due to a slight flexing of the floor of the monochromator housing as a result of changes in the differentıal pressure between the housing interior and the ambient external pressure. The data presented here have been corrected to account for changes in ambient pressure between calibrations.

Table 1 summarizes the instrument sensitivity, background, and $1 \sigma$ precision at the time of the VUV intercomparison. During the first intercomparison conducted earlier in the field study when the light source was in better condition, the sensitivity and precision were both significantly better, 175 counts per second (cps)/ppbv and 1.5 ppbv, respectively. Subsequent modifications to the instrument have improved the $1 \sigma$ precision to better than $1 \mathrm{ppbv}$ for a $1 \mathrm{~s}$ averaging period and eliminated the degradation in performance over time.

\subsection{Jülich C-130 VUV Fluorescence Instrument}

Gerbig et al. [1999] give a detailed description of the VUV resonance fluorescence instrument deployed aboard the U.K.
Meteorological Office C-130 aircraft. A schematic is shown in Figure 3 . Here we present only a short overview in context of differences from the NOAA approach. The instrument consists of the same principle components: a resonance discharge lamp (radio frequency rather than dc glow), an $\mathrm{N}_{2}$ purged optical filter (consisting of two dielectric coated mirrors in combination with two $\mathrm{CaF}_{2}$ lenses rather than a monochrometer), fluorescence chamber, and associated plumbing and calibration components. A combination of two suprasil lenses are used to image the fluorescence radiation onto the PMT cathode. To avoid interference of water vapor due to absorption of the fluorescence radiation $\left(5 \% / \% \mathrm{H}_{2} \mathrm{O}\right.$ in this instrument), the sampled air is dried by passıng it over a bed of Drierite. The fluorescence chamber, resonance lamp, and optical filter are connected to a four-stage membrane pump. In situ calibration of the instrument is achieved by injecting a standard (440 ppbv $\mathrm{CO}$ in air) into the sampling line, close to the control valve, at flow rates slightly higher than the sample flow rate. The in-flight standard was compared with a primary standard ( 1 ppm $\mathrm{CO}$ in air; Messer Grıesheım) before each flight. For determination of the background signal the calibration standard is passed through a Hopcalite scrubber, which quantitatively removes the $\mathrm{CO}$ to levels $<1$ ppbv. In addition, the background signal is determined by

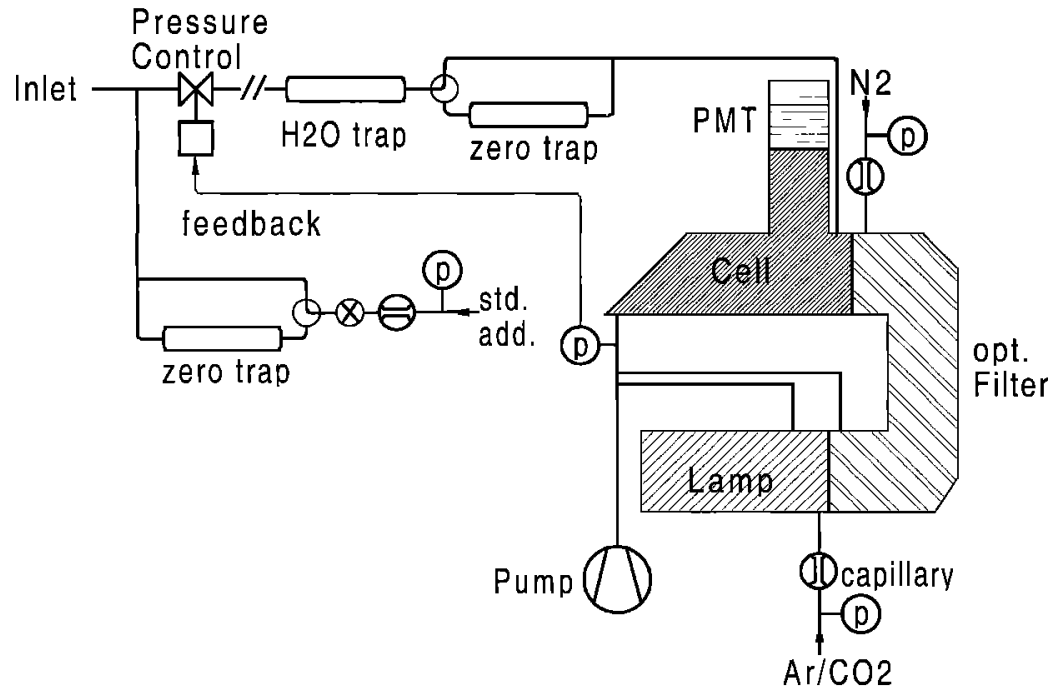

Figure 3. Schematic of Jülich C-130 VUV CO fluorescence instrument. 
switching a Hopcalite scrubber into the sample flow between the inlet tube and the fluorescence chamber. The flow rates of $\mathrm{N}_{2}$ and $\mathrm{CO}_{2} / \mathrm{Ar}$ are held constant by vacuum referenced pressure regulators and thermostatted capillaries. Table 1 compares the instrument measurement characteristics to those of the NOAA WP-3 instrument.

\section{VUV Fluorescence Versus TDLAS Intercomparison}

The intercomparison was conducted on September 2, 1997, as the NOAA WP-3 flew in transit from the NOAA Aircraft Operations Center in Tampa, Florida, to St. John's, Newfoundland, for the NARE 97 campaign. The TDLAS system on board the WP-3 was designed to measure formaldehyde during the field study. However, for the transit flight the instrument was specially configured to measure $\mathrm{CO}$ to provide an intercomparison with the VUV fluorescence data. Owing to this ad hoc arrangement, the resulting TDLAS CO data set does not represent optimal performance of that technique, but it does provide for an effective intercomparison of $\mathrm{CO}$ measurements by two techniques utilizing different physical principles. The transit flight track generally followed the eastern U.S. coast up to Virginia, turned east to approximately $300 \mathrm{~km}$ offshore, and then generally paralleled the coast for the remainder of the flight. The intercomparison was conducted informally, with frequent communication between the instrument operators. Field reductions of the data sets were compared, and the initial degree of agreement was assessed. The reduction of the final data presented here took place without further exchange of information.

Figure 4 displays the time series of $\mathrm{CO}$ mixing ratios measured by the two systems. Because of routine calibration and zeroing periods, as well as instrumental difficulties, coincident ambient data account for about $21 \%$ coverage of the 8.25 hour flight duration. However, they include 1269 independent $5 \mathrm{~s}$ average measurements from the continental and marine boundary layers and up to $\approx 7 \mathrm{~km}$ in the free troposphere. The sampled air parcels range from urban plumes encountered in continental outflow regions (the narrow, positive spikes in Figure 4) to subtropical air. The instruments recorded similar variations throughout the full $\mathrm{CO}$ range including during periods of rapid change, such as interception of the urban plumes. The VUV results are systematically higher than the TDLAS measurements; 92 ppbv versus $87 \mathrm{ppbv}$ on average for the entire data set. Figure 5 displays the correlation between the two data sets. The systematic difference between the two measurements is evident in the slope of the least squares line, which is about $7 \%$ above unity, while the systematic offset is about -1 ppbv. (All of the least squares analyses presented in this study utilize a bivariate regression that considers the error inherent in both variables [Neri et al., 1989], and regression coefficients are given with $2 \sigma$ confidence limits). The data sets are highly correlated; $\mathrm{r}^{2}=$ 0.97 .

Examination of the ratio of the measurements from the two instruments is a useful method to evaluate their precision and systematic differences. Figure 6 presents the ratio of the VUV measurements to the TDLAS measurements. An average systematic difference of $6 \%$ is indicated by the average value of the ratio (1.06), which is consistent with the slope and intercept from the linear correlation of the measurements. Since the instruments should be measuring exactly the same atmospheric concentrations, the standard deviation of the ratio of measurements, $\sigma=3.9 \%$, is expected to equal the square root of the sum of the squares of the relative precisions of each instrument. Thus neither instrument can have a precision worse than $3.9 \%$, and the root-mean-square precision of the two instruments is $2.8 \%$. Even though this agreement is quite good, the value of $\sigma$ expected from the estimated precisions of section 2 is only $1.9 \%$. Figure 6 a reveals periods when the scatter of the measurements is consistent with this expectation;

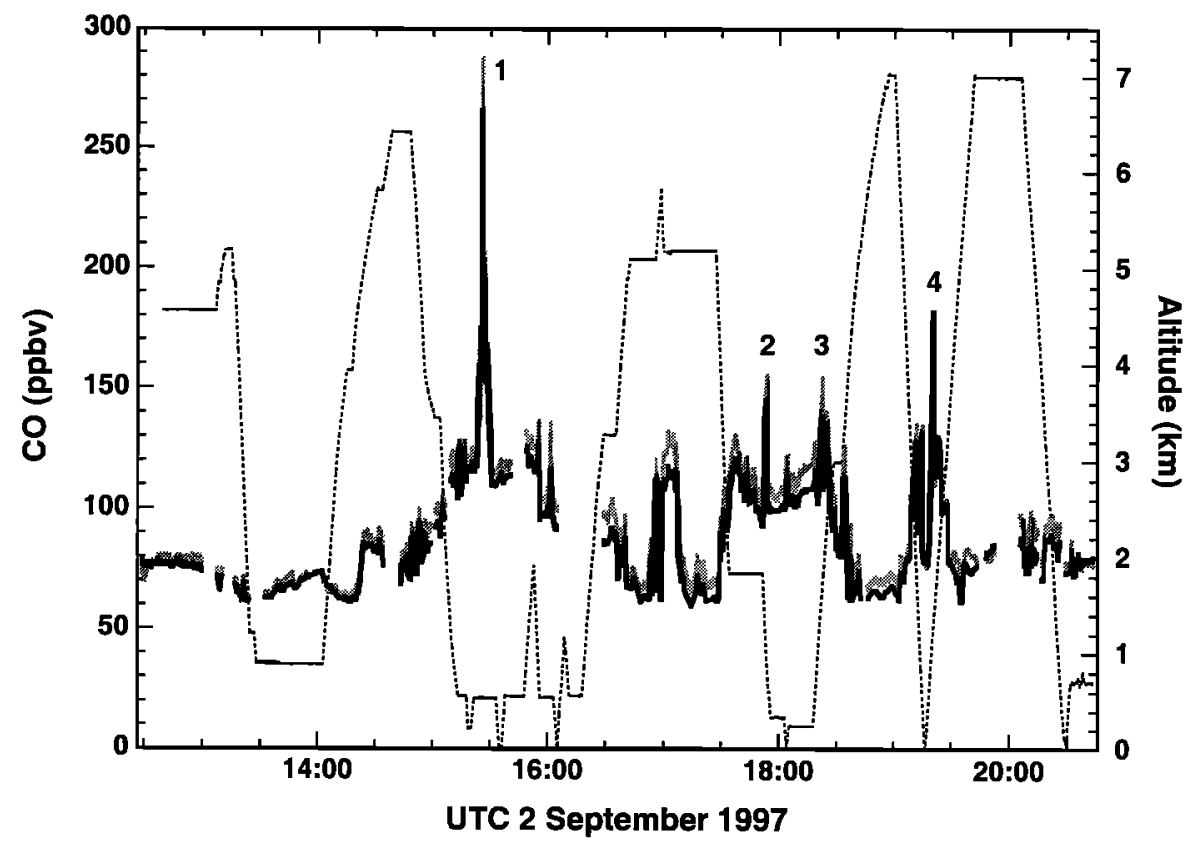

Figure 4. Time series of coincident $5 \mathrm{~s}$ average measurements of $\mathrm{CO}$ on the NOAA WP-3 transit flight. The solıd lines give the TDLAS (darker) and the VUV fluorescence (lighter) results, and the dotted line indicates the aircraft altitude. The features labeled 1 through 4 are intercepted urban plumes. 


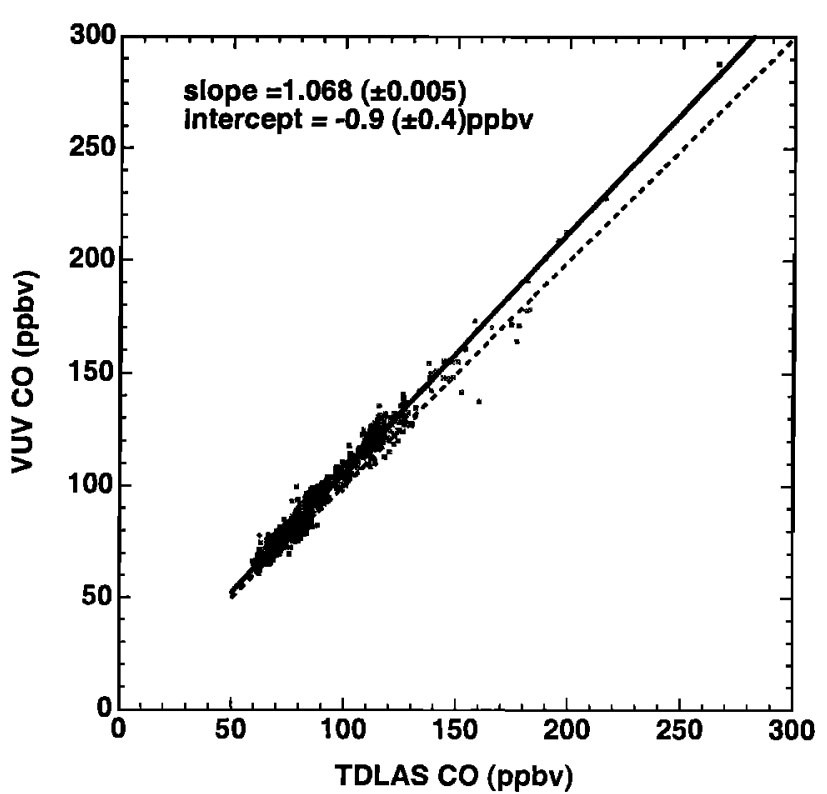

Figure 5. Correlation of the $5 \mathrm{~s}$ average measurements from the NOAA WP-3 transit flight. The dashed line gives the one to one correspondence. The solid line is the bivariate linear regression fit to the data; the parameters of this fit (with $2 \mathrm{~s}$ confidence limits) are given in the legend.

for example, during the first hour of the flight, $\sigma$ is $1.6 \%$, and between 1740 and $1805 \sigma=0.9 \%$, even as $\mathrm{CO}$ ranges from 95 to 150 ppbv. This behavior indicates that there are longerterm, systematic variations in the response of at least one of the instruments that are not accounted for by the calibration procedures. These variations are clear in the time series of Figure 6a. As discussed above, the TDLAS results were derived using a single flight calibration due to the large scatter in the 19 individual calıbrations. Hence it was not possible in the data reduction to account for any systematic variability in the sensitivity of the instrument. It is likely that some of the variability in the calıbrations was due to actual changes in the response of the instrument, and this information was lost. As a result, the measurement precision only achieved estimated values withın periods of tıme that are short in comparison to the drift in instrumental response.

Figures $6 b-6 d$ indicate the measurement ratio is independent of the $\mathrm{CO}$ concentration, but small correlations are found between the ratio and altitude $(0.56 \pm 0.11 \% / \mathrm{km}, 2 \mathrm{~s}$ confidence limit, $\left.r^{2}=0.08\right)$ and water vapor $(-2.1 \pm 0.3 \%$ $\mathrm{H}_{2} \mathrm{O}, r^{2}=0.16$ ). The dependence upon water vapor is unexpected. As discussed, spectroscopic specificity should prevent water interferences in the TDLAS measurement. The VUV system was tested for water sensitivity, and the small interference found $\left(-0.26 \pm 0.17 \% / \% \mathrm{H}_{2} \mathrm{O}\right)$ is much smaller than the relationship in Figure 6d. The apparent dependence on altitude and water may simply be accidental. The higher altitudes and drier air were encountered more frequently later in flight when the disagreement between the two instruments was at its largest.

\section{Intercomparison of Two VUV Fluorescence Instruments}

An interaircraft instrument intercomparison was conducted on September 18 in the central Atlantic between the NOAA
WP-3 flying from Newfoundland and the British Meteorological Office C-130 flying from the Azores. The flight plan commenced at $35.58^{\circ} \mathrm{E}, 44.00^{\circ} \mathrm{N}$ and consisted of four approximately north-south constant altitude legs of about 20 min each. Time was allowed at the beginning and end of each leg for instrument calibration. At the conclusion of the final leg, each aircraft descended to its lowest allowed altitude, and then climbed in unison. The intercomparison ended at $37.08^{\circ} \mathrm{E}, 44.63^{\circ} \mathrm{N}$. The two aircraft flew as close to each other as safety allowed; the horizontal and vertical separations averaged $110 \mathrm{~m}$ and $9.7 \mathrm{~m}$, respectively. Spatial variability of ambient $\mathrm{CO}$ on this scale is expected to be small in the central North Atlantic; however, it is possible that spatial variability may have contributed to the differences between the $\mathrm{CO}$ measurements. The flight directors aboard the separate planes were necessarily in contact throughout the intercomparison, and information of a general nature concerning immediate impressions of the concentration levels was exchanged. The $\mathrm{CO}$ data discussed in this section were exchanged through an independent third party; thus the results represent a double blind intercomparison.

Figure 7 shows the time series of the $5 \mathrm{~s}$ average mixing ratios measured during the intercomparison. These results are derived from 5157 coincident 1 s determinations, which represent $82 \%$ coverage of the intercomparison period. The missing periods are due to instrument calibrations and $6 \mathrm{~min}$ of lost data. The WP-3 CO data average is systematically lower than that of the C-130: 90.4 ppbv versus 92.5 ppbv. Figure 8 shows the correlation between the two data sets. The slope (0.961) and intercept (+1.4 ppbv) of the least squares fit to the data are consistent with the $2 \%$ difference in the respective averages. The relatively small $r^{2}$ value of 0.89 reflects the limited dynamic range of $\mathrm{CO}$ mixing ratios encountered durıng the intercomparison.

Figure 9 shows the ratio of the measurements from the two VUV CO systems. The average value of the ratio, 0.977 , is consistent with the other indications of the systematic agreement. The standard deviation of the ratio is $2.5 \%$, in excellent accord with the square root of the sum of the squares of the instrument precisions from Table $1(2.9 \%)$. Despite the agreement between the expected and observed variability in the ratio, there are small but significant systematic variations. The dependence of the ratio on water vapor in Figure $9 \mathrm{~d}(-0.85$ $\left.\pm 0.19 \% / \% \mathrm{H}_{2} \mathrm{O}\right)$ agrees well with that expected $\left(-1 \% / \% \mathrm{H}_{2} \mathrm{O}\right)$ from the different sampling approaches of the two instruments. The WP-3 instrument measures air at ambient humidity, while the $\mathrm{C}-130$ instrument dries the sample stream before measurement. When the WP-3 CO data are converted to mixing ratio in dry air, the measurement ratio exhibits negligible dependence on water $\left(+0.14 \pm 0.19 \% / \% \mathrm{H}_{2} \mathrm{O}\right)$, the dependence of the ratio on altitude apparent in Figure $9 c$ ( $0.46 \pm 0.08$ $\% / \mathrm{km})$ becomes negligible $(0.07 \pm 0.08 \% / \mathrm{km})$, and the average value of the ratio is 0.987 with a standard deviation of $2.5 \%$.

The CO mixing ratios recorded by the WP-3 instrument show two spikes of 4 to $6 \mathrm{ppbv}$ at approximately 1522 and 1524 UTC. These features are not present in the C-130 record and do not appear at the corresponding altitude during the previous descent. The agreement of the two instruments prior, between, and subsequent to the spikes is within 0.2-0.6 ppbv. The agreement between the two instruments throughout the rest of the intercomparison would seem to indicate that the spikes are real variations in ambient $\mathrm{CO}$ that were only sampled by the WP-3 instrument. An instrumental artifact 

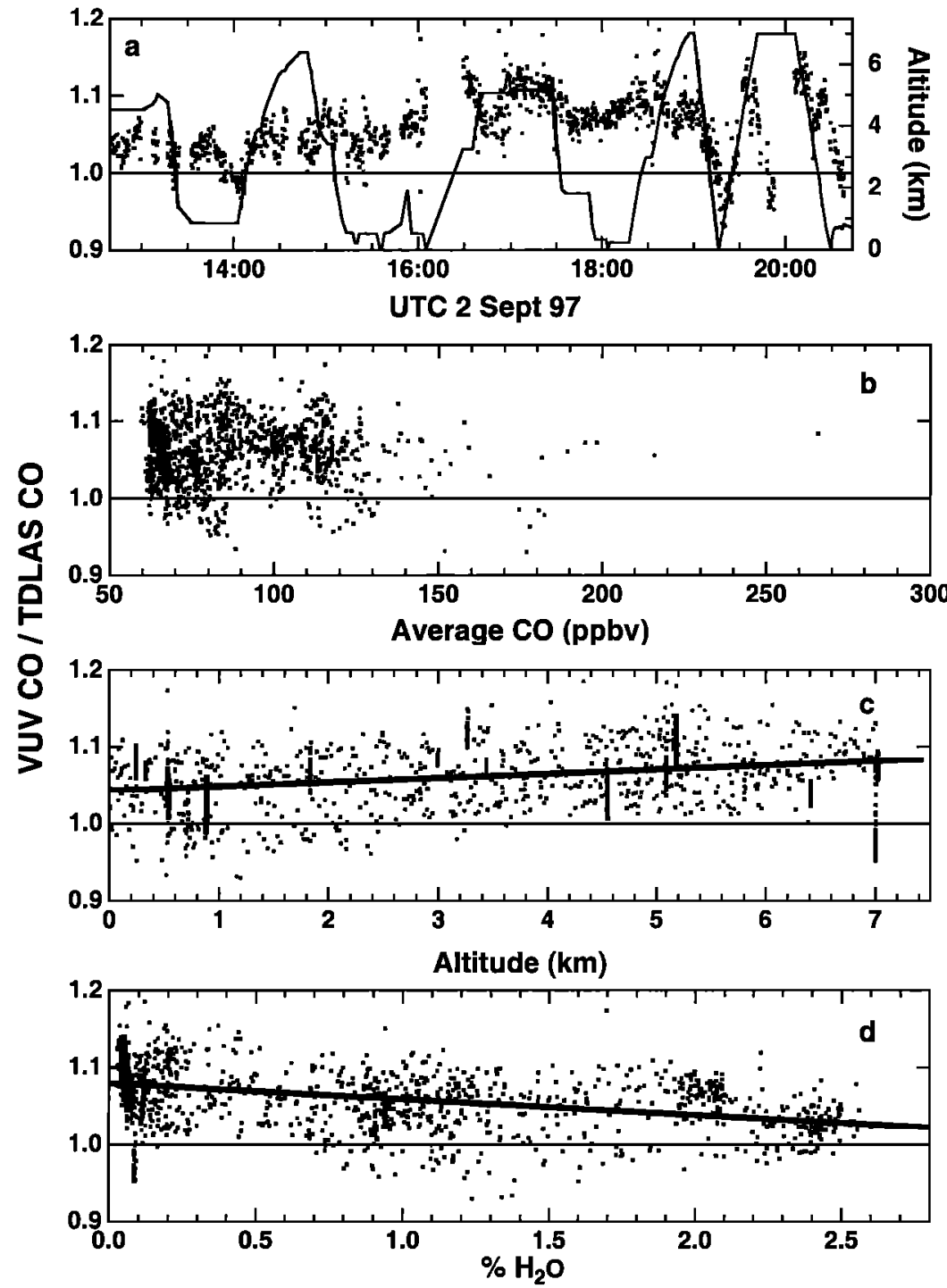

Figure 6. Ratio of coincident $5 \mathrm{~s}$ average $\mathrm{CO}$ measurements as a function of (a) time, (b) average CO concentration, (c) aircraft altitude, and (d) ambient water vapor. Linear least square fits are shown for the altitude and water vapor plots. The aircraft altitude is included as a solid line in Figure 6a.

cannot be ruled out, however. Short-term increases in discharge lamp intensity could cause such spikes. Subsequent to this study, a lamp intensity monitor has been installed in the NOAA WP-3 VUV fluorescence instrument to check for such transients

\section{Discussion and Conclusions}

The goal of this paper is to use the degree of agreement between the different $\mathrm{CO}$ measurements during the intercomparisons to assess the measurement accuracy and precision and the possibility of ambient interferences of the VUV fluorescence technique. Quantitative estimates of the accuracy and precision can be derived from the comparison of the two VUV systems with each other and with a TDLAS system. The consistent agreement of the instruments within estimated instrumental precisions indicates the absence of significant ambient interferences.

\subsection{Accuracy}

$\mathrm{CO}$ is a relatively inert gas, so reliable and stable standards are readily available, and handling of standards is not a great problem. Thus analysis of prepared samples can be considered almost routine. For example, in the blind intercomparison of the Measurement of Air Pollution From Satellite (MAPS) program, Novelli et al. [1998] found that nearly all of 11 participating laboratories analyzed four prepared mixtures of CO (50 to $200 \mathrm{ppbv}$ ) in air with an accuracy of $10 \%$ or better. The NOAA group in the present study participated in this MAPS intercomparison and reported results $5 \pm 1 \%$ above the reference analyses for all four samples. In the MAPS intercomparison we used a different measurement technique (NDIR), but the standard addition calibration technique was very similar, and the calibration was based upon the same SRM. Given this history, we conclude that the absolute accuracy of the present measurements can be adequately judged from the agreement achieved using three independent calibration standards and procedures.

An inaccuracy in one of the instruments in either intercomparison would be reflected by a systematic offset (i.e., a nonzero intercept in the linear correlations of Figures 5 and 8) or a proportional difference (i.e., a slope differing from unity in the linear correlations.) Figure 5 shows a small 


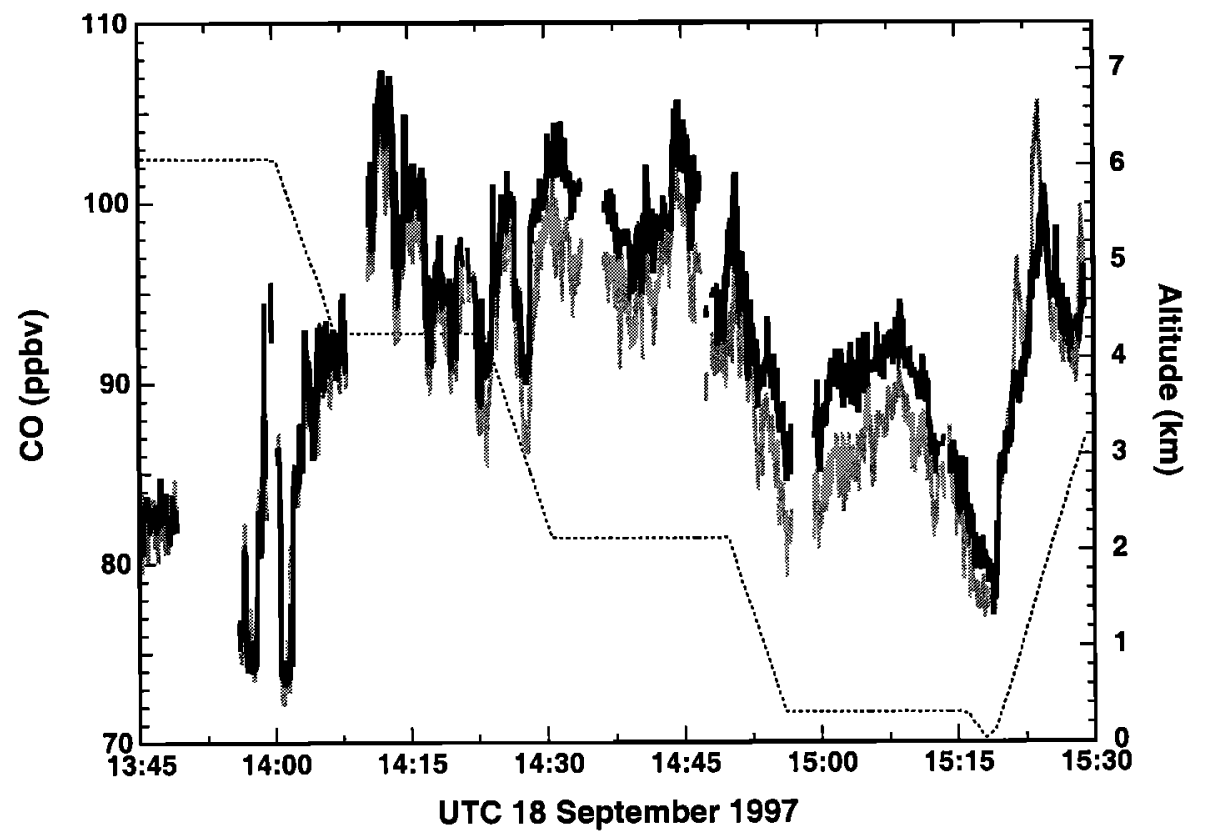

Figure 7. Time series of coincident $5 \mathrm{~s}$ average measurements of CO during the VUV instrument intercomparison. The solid lines give the C-130 (darker) and the WP-3 (lighter) results, and the dotted line is the aircraft altitude.

intercept of $-0.9 \pm 0.4 \mathrm{ppbv}(2 \sigma$ confidence limit). Thus it is concluded that the VUV technique suffers from, at worst, only a small systematic offset compared to the TDLAS technique. (The offset may be statistically equivalent to zero, since the confidence limit is derived assuming simple Gaussian statistıcs; as discussed earlier, the measurements exhibited differences that were correlated over time.) Also, we believe that the small positive intercept in Figure $8(1.4 \pm 0.8 \mathrm{ppbv})$ is not significant given the small dynamic range $(\approx 30 \mathrm{ppbv})$ and the

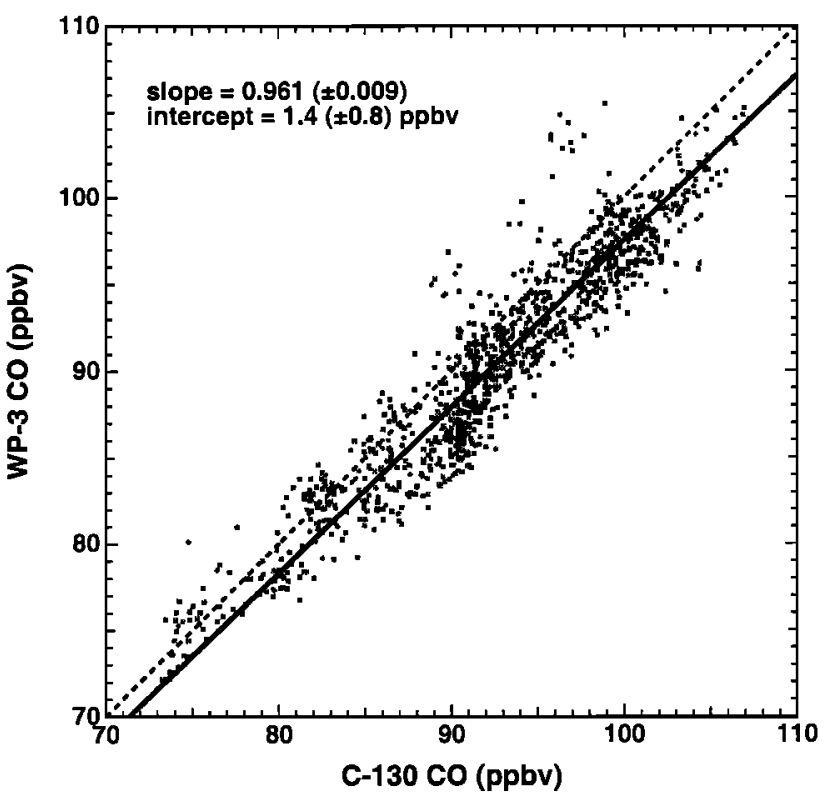

Figure 8. Correlation of the $5 \mathrm{~s}$ average measurements from the VUV instrument intercomparison. The dashed line gives the one to one correspondence. The solid line is the bivariate linear regression fit to the data; the parameters of this fit (with $2 \mathrm{~s}$ confidence limits) are given in the legend. relatively large extrapolation from the centroid of the data to the $y$ axis $(\approx 90 \mathrm{ppbv})$. In summary, none of the three instruments exhibits an offset larger than $1 \mathrm{ppbv}$, and thus we can interpret the average ratio of the measurements in each intercomparison as a measure of any proportional difference.

The ratio of the WP- 3 VUV to TDLAS measurements averaged 1.06 in the first intercomparison. In an attempt to resolve this $6 \%$ proportional difference, the standards used in the respective calibrations were directly compared subsequent to the field intercomparison. The NCAR and NOAA laboratory standard SRMs agreed to within $1.1 \%$, but the NOAA 9.9 ppmv freld standard was determined to be 10.37 ppmv. (A VUV instrument comparison between the field standard and the SRM made the original assignment. An error arose then due to the neglect of the dilution of ambient oxygen when the SRM, which was CO in nitrogen, was added to the sample stream. Since oxygen absorbs the excitation radiation, the instrument sensitivity was slightly higher when the SRM was added.) Upon correction of the VUV results for the 5\% error in the field standard, the WP-3 VUV results average $11 \%$ higher than those of the TDLAS system. This disagreement is likely due to imperfect mixing of the standard addition in the TDLAS inlet. In the second intercomparison the ratio of the WP- 3 to C-130 results (corrected to dry air mixing ratios) averaged 0.987 . Correction for the error in the WP-3 calibration standard moves the WP-3 results from $1.3 \%$ below to $3.4 \%$ above the $\mathrm{C}-130$ results.

In summary, the results of the NOAA WP-3 group averaged $3.4 \%$ above the $\mathrm{C}-130$ results, $11 \%$ above the TDLAS results, and $5 \%$ high in the MAPS intercomparison [Novelli et al., 1998]. This degree of agreement lends confidence to the accuracy of all of these results and, taken as a whole, indicate that the two VUV instruments measured accurately to within $5 \%$ or better. The TDLAS system may have been systematically low by a somewhat greater amount $(\approx 10 \%)$, but problems with the standard addition procedure in the inlet are believed responsible. 

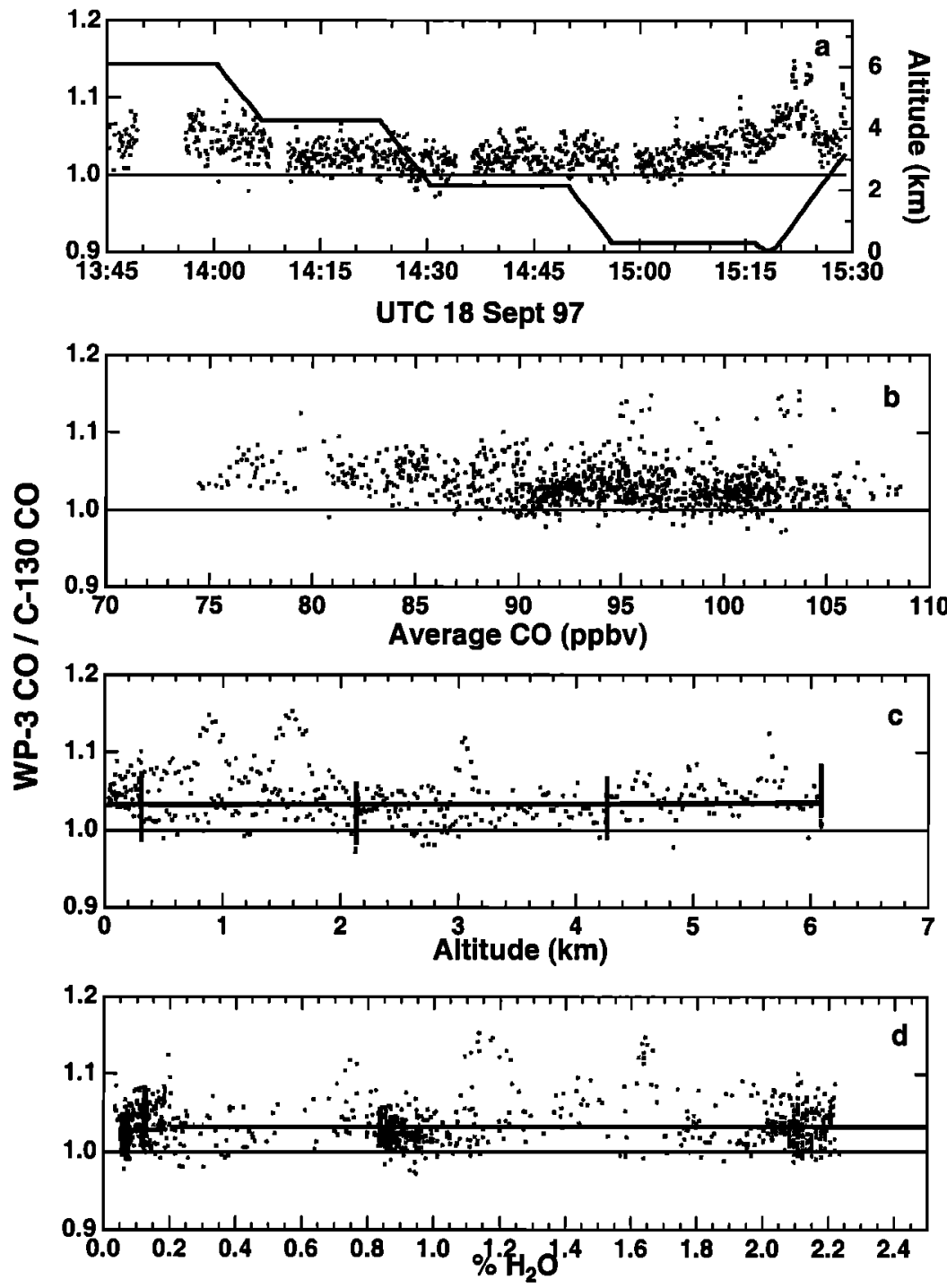

Figure 9. Ratios of coincident $5 \mathrm{~s}$ average $\mathrm{CO}$ measurements as a function of (a) time, (b) average $\mathrm{CO}$ concentration, (c) aircraft altitude and (d) ambient water vapor. Linear least square fits are shown for the altitude and water vapor plots. The aircraft altitude is included as a solid line in Figure 9a. Average values of the $\mathrm{CO}$ measurement ratio and water vapor concentration for constant altitude flight legs are indicated by the crosses.

\subsection{Precision}

The variability of the ratio of measurements from the VUV fluorescence intercomparison $(1 \sigma=2.5 \%)$ is consistent with the estimated precisions of 1.5 and $2.2 \mathrm{ppbv}$ for the $5 \mathrm{~s}$ average results of the C-130 and the WP-3 instruments, respectively. Taking the estimated precision of the WP-3 VUV instrument as accurate, the variability of the measurement ratio from the September 2 VUV/TDLAS intercomparison ( $1 \sigma=3.9 \%$ ) indicates a precision of approximately $3.6 \%$ for the TDLAS instrument. This value is within the range estimated for the TDLAS system as configured for $\mathrm{CO}$ measurements in this study (but certainly larger than is possible with an optimized TDLAS CO system). In summary, each of the three instruments are capable of $5 \mathrm{~s}$ average measurements with precisions smaller than $4 \%$, and the smaller quoted precisions of the VUV instruments are realistic estimates.

\subsection{Potential Interferences}

The excellent agreement of the instruments in both intercomparisons demonstrate that significant interferences in the measurements are absent over a wide range of air masses. In the VUV/TDLAS intercomparison the two techniques, based upon entirely different measurement principles, agreed well in air masses that ranged from the continental and marine boundary layer to $7 \mathrm{~km}$ in the midtroposphere. The boundary layer conditions included subtropical marine air with $\mathrm{CO}$ approaching $60 \mathrm{ppbv}$ and continental outflow with embedded urban plumes where $\mathrm{CO}$ approached 300 ppbv. The VUV intercomparison includes a much smaller range of air masses (marine boundary layer to midtroposphere in the midAtlantic) with a smaller $\mathrm{CO}$ range ( 72 to $107 \mathrm{ppbv}$ ), but provides an important comparison of instruments using the same physical technique implemented in contrasting styles. 
These contrasts included discharge lamps (dc versus radio frequency), optical filters (monochromator versus lens and dielectric coated mirrors), water treatment (ambient humidity versus drying over Drierite), and calibration procedures (standard addition versus sample replacement). This latter intercomparison of the two VUV instruments that differed widely in their design indicates that the VUV fluorescence technique for $\mathrm{CO}$ measurements is not particularly sensitive to the details of its implementation.

Acknowledgments. We wish to express our gratitude to Paul Novelli for facilitating the blind interchange of data from the intercomparison of September 18, 1997. Support for the NOAA and NCAR work comes from the NOAA Climate and Global Change Program. Christoph Gerbig acknowledges the support of the $\mathrm{C}-130$ flight hours funded by the NERC Thematic Program Atmospheric Chemistry Studies in the Oceanic Environment (ACSOE). This paper is listed as ACSOE publication ACP064.

\section{References}

Albritton, D.L., F C. Fehsenfeld, and A.F. Tuck, Instrumental requirements for global atmospheric chemistry, Science, 250, 75-81, 1990.

Dickerson, R.R., and A.C. Delany, Modification of a commercial gas filter correlation $\mathrm{CO}$ detector for enhanced sensitıvity, J. Atmos. Oceanic Technol., 5, 424-431, 1988.

Fink, E., Schwingungsrelaxation und Löschung elektronisch angeregter $\mathrm{CO}(A 1 \Pi)$ - und $\mathrm{NO}\left(A 2 \sum+\right)$ - Molekile in Strossen mit Edelgasatomen und einfachen Molekulen, Habilitationsschrift Univ. Bonn, Germany, 1976.

Fishman, J., and W. Seiler, Correlative nature of ozone and carbon monoxide in the troposphere: Implications for the tropospheric ozone budget, J. Geophys. Res., 88, 3662-3670, 1983.

Fried, A., B. Henry, D.D. Parrish, J.R. Carpenter, and M.P. Buhr, Intercomparison of tunable diode laser and gas $f_{l}$ lter correlation measurements of ambient carbon monoxide, Atmos. Environ., Part A, 25(10), 2277-2284, 1991 .

Fried, A., B.P. Wert, B. Henry, and J R. Drummond, Arborne tunable diode laser measurements of trace atmospheric gases, J. Soc. PhotoOpt. Instrum Eng., 3285, 154-162, 1998a.

Fried, A., B. Henry, B.P. Wert, S. Sewell, and J.R. Drummond, Laboratory, ground-based, and airborne tunable diode laser systems: Performance characteristics and applications in atmospheric studies, Appl. Phys. B, 67, 317-330, 1998b.

Fried, A , B.P. Wert, B. Henry, and J. R. Drummond, Airborne tunable diode laser measurements of formaldehyde, Spectrochim. Acta, Part $A, 55,2097-2110,1999$.

Gerbig, C., D. Kley, A. Volz-Thomas, J. Kent, K. Dewey, and D.S. McKenna, Fast-response resonance fluorescence $\mathrm{CO}$ measurements aboard the C-130: Instrument characterization and measurements made during North Atlantic Regional Experiment 1993,J Geophys. Res., 101, 29,229-29,238, 1996.

Gerbig, C., S Schmitgen, D. Kley, A. Volz-Thomas, K. Dewey, and D. Haaks, An improved fast-response vacuum-UV resonance fluorescence CO instrument, J. Geophys. Res., 104, 1699-1704, 1999.

Hoell, J. M., Jr., G. L. Gregory, D. S. McDougal, G. W. Sachse, G F. Hill, E. P. Condon, and R. A. Rasmussen, Airborne intercomparison of carbon monoxide measurement tehcniques, J. Geophys. Res., 92 , 2009-2019, 1987.

Imhof, R.E., and F.H. Read, Measured lifetimes of the first seven vibrational levels of $\mathrm{A} 1 \Pi$ state of CO, Chem. Phys. Lett., 11, 326328,1971

Inn, E.C.Y., K. Watanabe, and M. Zelikoff, Absorption coefficients of gases in the vacuum ultraviolet, Part III, $\mathrm{CO}_{2}, J$. Chem. Phys., 21, $1648-1653,1953$.
Neri, F., G. Saitta, and S. Chiofalo, An accurate and straightforward approach to line regression analysis of error-affected experimental data, J. Phys. E Sci. Instrum., 22, 215-217, 1989.

Newell, R. E., et al., Vertical fine-scale atmospheric structure measured from NASA DC-8 during PEM-West A, J. Geophys. Res., 101, 1943-1960, 1996.

Nicholls, R W., Laboratory astrophysics, J. Quant. Spectrosc. Radiat. Transfer, 2, 433-449, 1962.

Novelli, P.C., L P Steele, and P.P. Tans, Mixing ratios of carbon monoxide in the troposphere, J. Geophys. Res., 97, 20,731-20,750, 1992.

Novelli, P. C., et al., An internally consıstent set of globally distributed atmospheric carbon monoxide mixing ratios developed using results from an intercomparison of measurements, J. Geophys. Res., 103, $19,285-19,293,1998$.

Okabe, H., Photochemistry of Small Molecules, John Wiley, New York, 1978

Parrish, D. D., J. S. Holloway, M. Trainer, P C. Murphy, G. L. Forbes, and $F \mathrm{C}$. Fehsenfeld, Export of North American ozone pollution to the North Atlantic Ocean, Science, 259, 1436-1439, 1993.

Parrish, D.D., J.S. Holloway, and F.C. Fehsenfeld, Routine, continuous measurement of carbon monoxide with parts per billion precision., Environ. Sci. Technol., 28(9), 1615-1618, 1994.

Parrish, D.D., M. Trainer, J.S. Holloway, J.E. Yee, M.S. Warshawsky, F.C. Fehsenfeld, G. Forbes, and J.L. Moody, Relationships between ozone and carbon monoxide at surface sites in the North Atlantic region, J. Geophys. Res., I03, 13,357-13,376, 1998.

Rasmussen, R.A., and M.A.K. Khalil, Atmospheric trace gases at Point Barrow and Arctic haze, in Geophysical Monitoring for Climatic Change, No. 10 Summary Report 1981 , edited by B.A. Bodhaine and J. Harris, pp. 114-120, U.S. Dep. of Transp, Washington, D. C., 1982.

Rothman, L. S, et al., The HITRAN molecular spectroscopic database and HAWKS (HITRAN Atmospheric Workstation): 1996 edition, $J$. Quant. Spectrosc. Radiat. Transfer, 60, 665-710, 1996.

Sachse, G. W., G. F. Hill, L. O. Wade, and M. G. Perry, Fast-response, high-precision carbon monoxide sensor using a tunable diode laser absorption technique, J. Geophys. Res., 92, 2071-2081, 1987.

Seinfeld, J. H., Atmospheric Chemistry and Physics of Air Pollution, John Wiley, New York, 1986.

Singh, H. B., et al, Impact of biomass burning emissions on the composition of the South Atlantic troposphere Reactive nitrogen and ozone, J. Geophys Res , 101, 24,203-24,219, 1996.

Volz, A., and D. Kley, A resonance-fluorescence instrument for the insitu measurement of atmospheric carbon monoxide, J. Atmos. Chem., $2,345-357,1985$.

Watanabe, K., and M. Zelikoff, Absorption coefficients of water vapor in the vacuum ultraviolet, J. Opt. Soc. Am., 43, 753-755, 1953.

Wert, B P., A. Fried, B. Henry, and J R. Drummond, Airborne measurements of tropospheric formaldehyde by tunable diode laser absorption spectroscopy, J. Soc. Photo-Opt. Instrum. Eng., 2834, 175-186, 1998.

J. R. Drummond, Dept. of Physics, University of Toronto, $60 \mathrm{St}$. George, Toronto, Ontario, Canada M5 51A7. (e-mail: jim@atmosp.physics.utoronto.ca).

A. Fried, B. Henry, and B. Wert, National Center for Atmospheric Research, P.O. Box 3000 , Boulder, CO 80307.

C. Gerbig, Department of Earth and Planetary Sciences, Division of Engineering and Applied Sciences, Harvard University, Cambridge, MA 02138.

J. S. Holloway, R. O. Jakoubek, and D.D. Parrish, Aeronomy Laboratory, NOAA, Boulder, CO 80303. (e-mail: parrish@al.noaa.gov).

S. Schmitgen and A. Volz-Thomas, Instutut für Chemie und Dynamik der Geosphåre, Forschungszentrum Jülich, Jülich, Germany D52425. (email: a.volz-thomas@kfa-juelich.de).

(Received December 20, 1999; revised April 12, 2000; accepted April 12, 2000.) 